Brazilian Journal
of Chemical
Engineering

\title{
PRODUCTION OF SURFACTIN BY Bacillus subtilis MTCC 2423 FROM WASTE FRYING OILS
}

\author{
N. Vedaraman ${ }^{1}$ and N.Venkatesh ${ }^{2 *}$ \\ ${ }^{1}$ Chemical Engineering Division, Central Leather Research Institute, \\ Chennai - 600020, India. \\ ${ }^{2}$ Department of Chemical Engineering, St. Joseph's College of Engineering, \\ Phone: 9144 24866132, Fax: 0091-41-24960344, Chennai - 600119, India. \\ E-mail: chemvenkatesh@gmail.com
}

(Submitted: April 12, 2010 ; Revised: January 14, 2011 ; Accepted: January 28, 2011)

\begin{abstract}
One of the obstacles in the way of wide scale industrial application of biosurfactants is the high production cost coupled with a low production rate. In order to lower the production cost surfactin production by Bacillus subtilis MTCC 2423 was studied in submerged batch cultivation using waste frying oils. It was observed that the decrease in surface tension was $56.32 \%, 48.5 \%$ and $46.1 \%$ with glucose, waste frying sunflower oil and waste frying rice bran oil, respectively. Biomass formation was $4.36 \mathrm{~g} / \mathrm{L}, 3.67 \mathrm{~g} / \mathrm{L}$ and $4.67 \mathrm{~g} / \mathrm{L}$ for glucose, waste frying sunflower oil and waste frying rice bran oil, respectively. Product yield (g product/g substrate) was $2.1 \%, 1.49 \%$ and $1.1 \%$ with glucose, waste frying sunflower oil and waste frying rice bran oil as substrates. This process facilitates safe disposal of waste frying oil, as well reducing the production cost of surfactin.
\end{abstract}

Keywords: Biosurfactants; Bacillus subtilis; Surface Tension; Waste frying oils; Secondary metabolite.

\section{INTRODUCTION}

Surfactants are amphipathic substances containing both hydrophobic and polar groups that absorb to and alter the conditions prevailing at interfaces (Rosenberg and Ron, 1989). The effectiveness of a surfactant is determined by its ability to lower the surface tension, which is a measure of the surface free energy per unit area required to bring a molecule from the bulk phase to the surface (Mulligan, 2005). The majority of chemical surfactants are environmentally objectionable compounds. Increased environmental awareness and strict legislation has made environmental compatibility of surfactants an important factor in their various applications.

The unique properties of biosurfactants allow their use and the possible replacement of chemically synthesized surfactants in a great number of industrial applications (Kosaric, 1992). The reasons for their popularity, as high value microbial products, are primarily their specific action, low toxicity, relative ease of preparation and widespread applicability (Peypoux et al., 1999). They can be used as emulsifiers, demulsifiers, wetting agents, spreading agents, foaming agents, functional food ingredients and detergents in various industrial sectors such as petroleum and petrochemicals, organic chemicals, foods and beverages, cosmetics and pharmaceuticals, mining and metallurgy, agrochemicals and fertilizers, environmental control and many others (Banat et al., 2000).

The history of surfactin dates back to 1968 , when the presence of a new biologically active compound in the culture broth of Bacillus subtilis strain was reported for the first time. Studies on the biosynthesis of surfactin began with the work of Kluge et al. (1988), who proposed a non-ribosomal mechanism catalyzed by multienzymatic thiotemplates constituting the surfactin synthetase. Surfactin is produced in a nucleic acid independent

*To whom correspondence should be addressed 
way through the use of large enzyme complexes called surfactin synthetase complex (Steller et al., 2004). Surfactin's structure consists of a peptide loop of seven amino acids and a hydrophobic fatty acid chain with thirteen to sixteen carbons. The seven amino acids are L-glutamine, L-leucine, D-leucine, L-valine, L-asparagine, D-leucine, and L-leucine. The hydrophobic amino acid residues leucine and valine are located at positions 2, 3, 4, 6 and 7 while the hydrophilic glutamyl and aspartyl residues are at positions 1 and 5, respectively. Because of this structure, surfactin is one of the most powerful biosurfactants and is capable of lowering the surface tension of water from $72 \mathrm{mN} / \mathrm{m}$ to $22 \mathrm{mN} / \mathrm{m}$ at a concentration as low as $20 \mu \mathrm{M}$ (Peypoux et al., 1999).

The choice of inexpensive raw materials is important to the overall economics of the process because they account for nearly $50 \%$ of the final product cost (Makkar and Cameotra, 1999). World production of oils and fats is about 120 million tonnes, $81 \%$ of which are derived from plants (Brackmann and Deutschland, 2004). Most of the oils and fats are used in the food industry, which generates great quantities of waste frying oils. The disposal of these waste frying oils is a growing problem, which explains the increasing interest in the use of waste frying oils for microbial transformation. In this paper, detailed studies have been made on the reuse of waste frying sunflower oil (WFSFO) and waste frying rice bran oil (WFRBO) as substrates for surfactin production using Bacillus subtilis.

\section{MATERIALS AND METHODS}

\section{Organism}

Bacillus subtilis MTCC 2423 was obtained from the Microbial Type Culture Collection (MTCC), Institute of Microbial Technology, Chandigarh, India. The culture was maintained on nutrient agar plates, as per the recommendations of the supplier, and stored on agar slants at $4^{\circ} \mathrm{C}$ for further use. WFSFO and WFRBO were chosen as substrates for the study and were obtained from a local restaurant. The choice of substrates was driven by the fact that both are non-conventional sources and are easily available and inexpensive.

\section{Media and Cultivation Conditions}

The culture was grown in a $250 \mathrm{ml}$ Erlenmeyer flask with $50 \mathrm{~mL}$ of medium for 24 hours on a rotary shaker at $160 \mathrm{rpm}$ and $30^{\circ} \mathrm{C}$. The nutrient broth used was beef extract $(1 \mathrm{~g} / \mathrm{L})$, yeast extract $(2 \mathrm{~g} / \mathrm{L})$, peptone $(5 \mathrm{~g} / \mathrm{L})$ and sodium chloride $(5 \mathrm{~g} / \mathrm{L})$. All the chemicals were obtained from Hi Media, Mumbai, India. This was used as inoculum at 5\% level at an absorbance of 0.85 at $600 \mathrm{~nm}$. Submerged batch cultivation experiments were conducted in $500 \mathrm{~mL}$ Erlenmeyer flasks containing $100 \mathrm{~mL}$ of medium. The concentration of the medium was: glucose/WFSFO/WFRBO (50 g/L), yeast extract $(5 \mathrm{~g} / \mathrm{L}), \mathrm{KH}_{2} \mathrm{PO}_{4}(1 \mathrm{~g} / \mathrm{L}), \mathrm{MgSO}_{4} .7 \mathrm{H}_{2} \mathrm{O}(0.5 \mathrm{~g} / \mathrm{L})$, $\mathrm{CaCl}_{2}(0.1 \mathrm{~g} / \mathrm{L}), \quad \mathrm{NaCl}(0.1 \mathrm{~g} / \mathrm{L})$, and peptone $(0.7 \mathrm{~g} / \mathrm{L})$. Three separate flasks, one with glucose as control and the other two with WFSFO and WFRBO, were prepared and sterilized at $121^{\circ} \mathrm{C}$. The final $\mathrm{pH}$ was adjusted to 7.2. After adding the inoculum, the flasks were incubated on a rotary shaker at a speed of $160 \mathrm{rpm}$ for five days.

\section{Biomass, Residual Glucose and Residual Oil Determination}

The liquid from the culture was taken once in a day, centrifuged at $12900 \times \mathrm{g}$ and the cell pellet obtained was oven dried at $105^{\circ} \mathrm{C}$ overnight and then weighed to quantify the dry cell biomass. The supernatant was used to analyze residual glucose concentration in the sample by the anthrone method (Roe, 1955). Residual oil was extracted using hexane as solvent. Residual oil was quantified after removing solvent in a rotary evaporator at $40^{\circ} \mathrm{C}$ (Garcia-Ochoa and Casas, 1999). All the experiments were performed in duplicate and the average values are reported.

\section{Surface Activities}

Reduction in surface tension was observed every day for a period of five days. Surface tension measurements were made by the $\mathrm{Du}$ Noüy-ring method using a surface tension balance - interfacial tensiometer with a $4 \mathrm{~cm}$ platinum ring as per Indian standard methods ((IS) 6104 and American Society for Testing and Materials (ASTM) D 971 specifications) at room temperature. A platinum wire ring was placed into the solution and then slowly pulled through the liquid-air interface. Stabilization was allowed to occur until the standard deviation of 10 successive measurements was less than $0.4 \mathrm{mN} / \mathrm{m}$. Between two consecutive measurements, the platinum ring was rinsed with water and acetone and allowed to dry. All the measurements were made on cell-free broth obtained by centrifuging the cultures at $12900 \times \mathrm{g}$ for $20 \mathrm{~min}$. 
Surfactin Isolation, Purification and Characterization

Crude surfactin was recovered by acid precipitation. The entire cultivation broth was centrifuged at $12900 \times \mathrm{g}$ at $4^{\circ} \mathrm{C}$ for 20 minutes to remove the cells. The $\mathrm{pH}$ of cell-free culture broth was adjusted to 2 using $6 \mathrm{~N}$ hydrochloric acid and left overnight at $4^{\circ} \mathrm{C}$ for decantation. The liquid phase was then centrifuged at $12900 \times \mathrm{g}$ for $20 \mathrm{~min}$ and the precipitate was neutralized using $1 \mathrm{~N}$ sodium hydroxide solution, and freeze dried. After drying, the solid residue was redistributed in a solution of chloroform/methanol $65: 15$ and filtered though Whatman number 1 filter paper. After filtering, the permeate was dried at $50^{\circ} \mathrm{C}$. The solid residue was triturated, weighed and stored frozen for subsequent analysis (Makkar and Cameotra, 1997). For characterization of surfactin, thin layer chromatography was used with a commercial surfactin standard obtained from Sigma, USA. TLC studies on silica gel 60 employed, as the analytical solvent for elution, chloroform/methanol/propanol/ $\quad 0.25 \% \quad \mathrm{KCl} /$ ethyl acetate $(25 / 13 / 25 / 9 / 25, \mathrm{v} / \mathrm{v} / \mathrm{v} / \mathrm{v} / \mathrm{v}) \quad$ Surfactin were detected as white spots by spraying with water followed by gentle heating (Bonmatin et al., 1995).

\section{RESULTS AND DISCUSSION}

Time course studies of dry cell biomass formation, surfactin production, surface tension reduction and substrate utilization by the culture media of Bacillus subtilis MTCC 2423 grown with three carbon sources, glucose, WFSFO and WFRBO, at $160 \mathrm{rpm}$ and $30^{\circ} \mathrm{C}$ are represented in Figures 1 to 3 . The experiment was carried out in duplicate and the average results are reported. It has been shown previously that surfactin is secreted by Bacillus during the stationary phase when nutrients in the culture medium are limited (Seydlová and Svobodová 2007). There was a considerable amount of surfactin synthesis during the late exponential phase, but the maximum amount of surfactin production was seen during the stationary phase. The maximum surfactin production reported from Bacillus subtilis using 4\% carbon substrate and 0.3\% nitrogenous substrate at $30^{\circ} \mathrm{C}$ was $808 \mathrm{mg} / \mathrm{L}$ (Makkar and Cameotra, 1998). In the present work, $5 \%$ glucose and $0.5 \%$ of yeast extract resulted in $983 \mathrm{mg} / \mathrm{L}$ of surfactin. About $54.6 \%$ of glucose was utilized in the first 24 hours, whereas in the rest of the incubation time about $41.2 \%$ of the substrate was utilized. $74 \%$ of the biomass was formed within the first 48 hours, whereas the next 116 hours contributed to $26 \%$ of the biomass. Yield of biomass based on glucose (g biomass/g substrate) was 0.091 and the yield of surfactin based on biomass ( $g$ surfactin/g biomass) was 0.23 . Yield of surfactin based on glucose ( $g$ of surfactin/g glucose) was 0.021 . Surface tension reduction by surfactin produced by Bacillus subtilis after 72 hours at $30^{\circ} \mathrm{C}$ was reported to be $39 \%$. (Joshi et al., 2008). In the present studies, glucose substrate with Bacillus subtilis MTCC 2423 produced a reduction of $56.32 \%$. Surface tension was reduced to the minimum value within the first 48 hours, after reaching the critical micelle concentration.

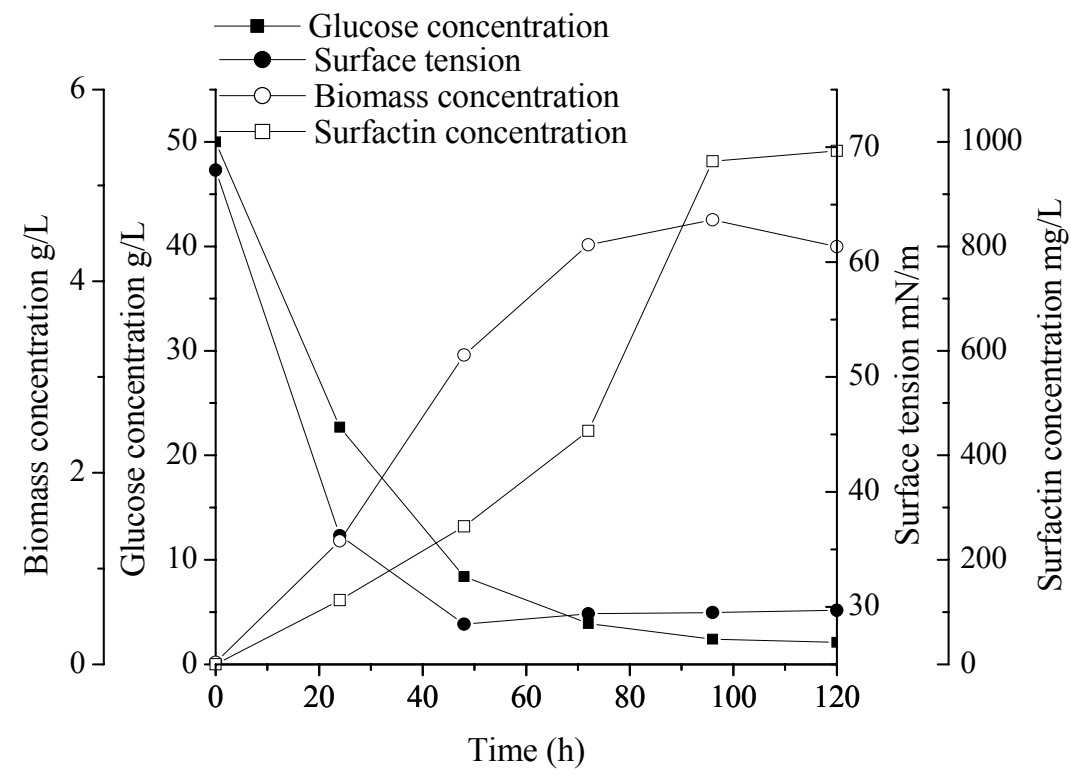

Figure 1: Profiles of utilization of glucose, biomass growth, reduction in surface tension and surfactin production in submerged cultivation as a function of time 


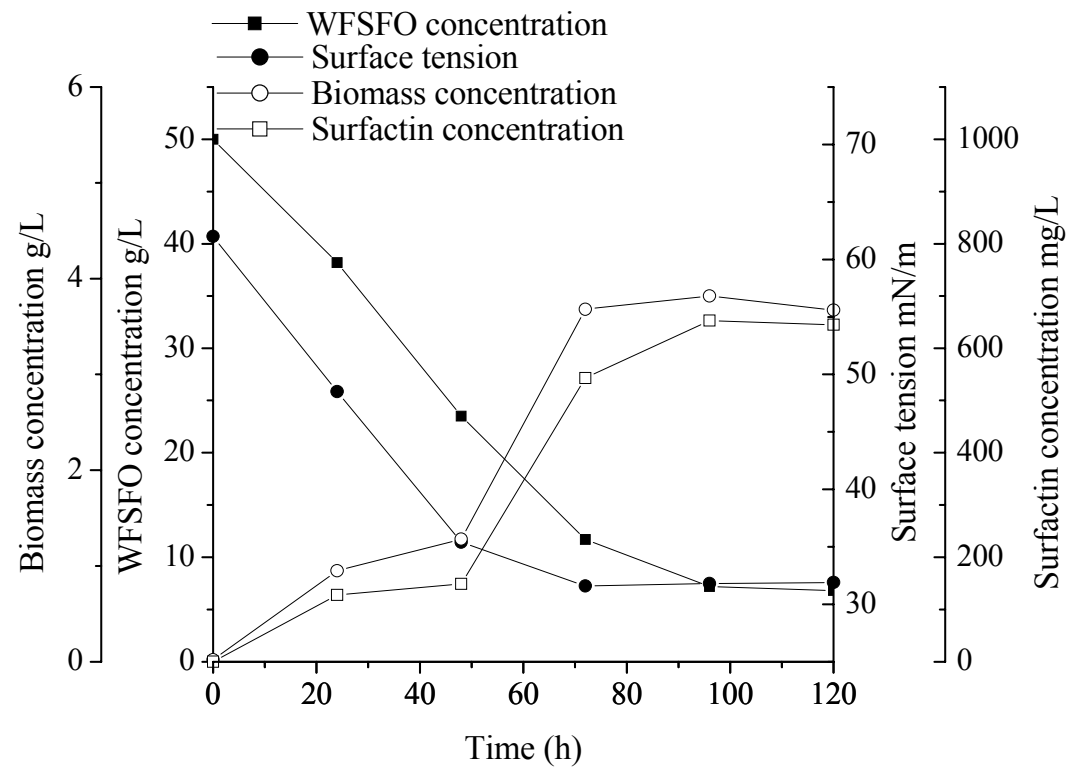

Figure 2: Profiles of utilization of WFSFO, biomass growth, reduction in surface tension and surfactin production in submerged cultivation as a function of time

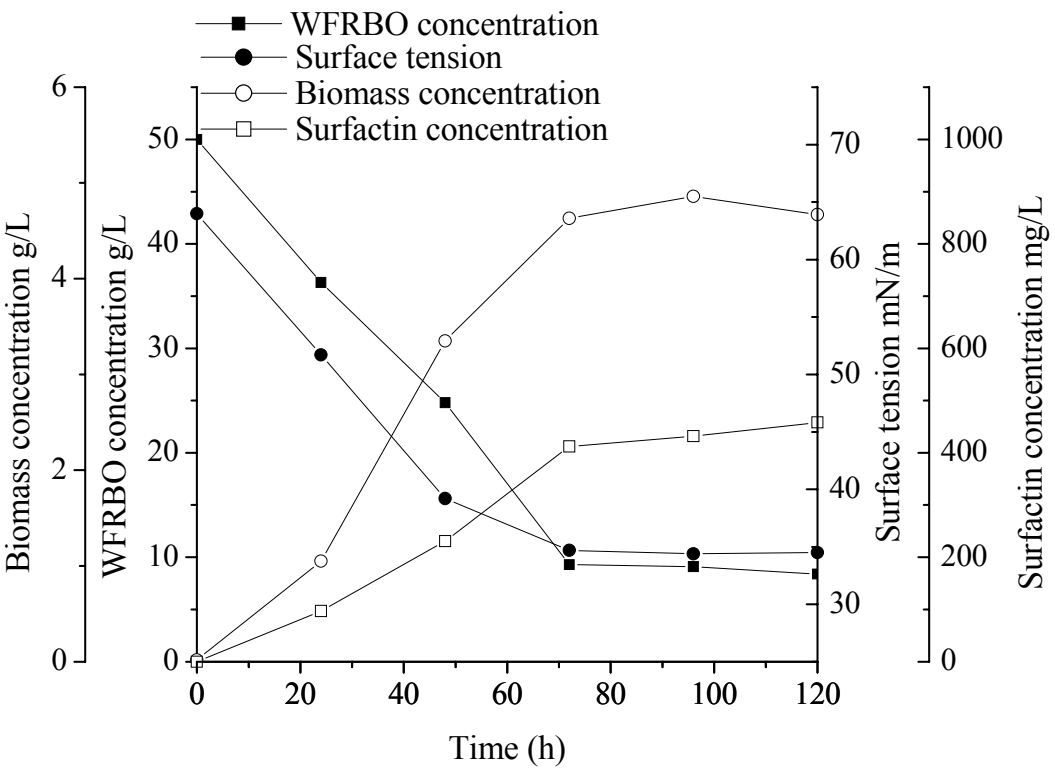

Figure 3: Profiles of utilization of WFRBO, biomass growth, reduction in surface tension and surfactin production in submerged cultivation

Usage of waste frying oils for the production of biosurfactants was first demonstrated by Fleurackers (2006), who produced sophorolipids from Candida bombicola. Later, rhamnolipids were successfully synthesized from Pseudomonas aeruginosa grown on waste frying oil (Raza et al, 2006). Pure paraffin oil and cotton seed oil were used as substrates for the production of surfactin using Bacillus subtilis (Joshi et al, 2008). In the present work, waste frying sunflower oil and waste frying rice bran oil were successfully used to grow Bacillus subtilis MTCC 2423 and to produce surfactin. Generally, oils, being hydrophobic, exhibit prolonged resistance against biodegradation due to their low water solubility, which increases their adsorption to cell surfaces and limits their availability to degrading microorganisms. Only about $23.4 \%$ of WFSFO was utilized during the first 24 hours. As the production of surfactin started, 
consumption of oil increased and $62.8 \%$ of oil was successfully consumed during the rest of the incubation period. (Figure 2). This might be attributed to an increase in the lipophilic (oil attracting) nature of the of the cell surface, due to the production of surfactin in traces, thereby increasing direct physical contact with the emulsified substrate; alternatively it may increase the bioavailability of the hydrophobic substrates by increasing their solubility (Shreve et al., 1995). During the first 48 hours, $34.9 \%$ of the biomass was formed and the remaining $65.1 \%$ of biomass was formed in the rest of the incubation period. The increase in surfactin production resulted in emulsification of the culture broth, which facilitates the microbial access to the substrate, resulting in the utilization of the substrate and increased biomass formation. Yield of biomass based on WFSFO (g biomass/g substrate) was 0.085 , and yield of surfactin based on biomass (g surfactin/g biomass) was 0.18 . Yield of surfactin based on WFSFO (g of surfactin/g WFSFO) was 0.015 . Surface tension reduction by surfactin was only about $48.5 \%$ and the final surface tension of the cell free culture broth was $31.9 \mathrm{mN} / \mathrm{m}$. Previous studies have shown that the carbon source has a profound effect on the chemical structure and properties of the biosurfactant produced. In the case of surfactin, it has been shown that the activity of surfactin was increased when L-valine at the fourth position was substituted by leucine and isoleucine (Bonmatin et al., 1995). A possible structural difference in the surfactin produced with WFSFO may have resulted in the low surface tension reduction.

Bacillus subtilis grown with WFRBO produced $71.7 \%$ of the biomass in the first 48 hours and $28.3 \%$ of the biomass in the rest of the incubation period (Figure 3). As reported by Zigoneanu et al. (2008), rice bran oil contains vitamin $\mathrm{E}$ and oryzanol, which aids the growth of the biomass. But the fast growth of biomass did not yield an equivalent amount of surfactin. Yield of biomass based on WFRBO ( $\mathrm{g}$ biomass/g substrate) was 0.11 and yield of surfactin based on biomass ( $g$ surfactin/g biomass) was 0.098. Yield of surfactin based on WFRBO (g of surfactin/g WFRBO) was 0.011. Surface tension reduction by surfactin was only about $46.1 \%$ and the final surface tension of the cell free culture broth was $34.5 \mathrm{mN} / \mathrm{m}$. The colour of the crude surfactin obtained was not as white as the commercial sample and the critical micelle concentration was higher by $12 \%$ compared to the commercial sample. Conventional and costly substrates can be successfully substituted by cheap carbon sources, like waste frying oils to synthesize useful byproducts (Liu et al, 2009). To increase the yield of surfactin, biomass generation has to be restricted and substrate consumption by the available microbes has to be increased. Low cost raw materials for production of biosurfactants may not only minimize industrial pollutants, but also simultaneously generate extremely useful and value added products.

\section{CONCLUSIONS}

Large quantities of biosurfactants are particularly required in petroleum and environmental applications, which, due to the bulk use, may be expensive. To overcome this problem, processes should be coupled to the utilization of waste substrates, combating at the same time their polluting effect, which balances the overall costs. The present work has shown that waste friyng oils can be successfully used to synthesize surfactin from Bacillus subtilis. Even though the purity of the product obtained was inferior, as compared to surfactin obtained from conventional substrates, crude biosurfactant itself can be directly utilized in most applications related to the oil industries and bioremediation.

\section{REFERENCES}

Banat, I. M., Makkar, R. S., Cameotra, S. S., Potential commercial applications of microbial surfactants. Appl. Microbiol. Biotechnol., 53, 495-508 (2000).

Bonmatin, J., Labbé, H., Grangemard, I., Peypoux, F., Maget-Dana, R., Ptak, M., Michel, G., Production, isolation and characterization of [Leu (5)] surfactins and [Ile (4)] surfactins from Bacillus subtilis. Lett. Pept. Sci., 2, 41-47 (1995).

Brackmann, B., Deutschland, C., Proceedings $6^{\text {th }}$ world surfactant congress CESIO. Berlin, Germany, June 21-23, paper number 112 (2004).

Fleurackers, S. J. J., On the use of waste frying oil in the synthesis of sophorolipids. Eur. J. Lipid. Sc. Technol., 108, 5-12 (2006).

Garcia-Ochoa, F., Casas, J. A., Unstructured kinetic model for sophorolipid production by Candida bombicola, Enzyme. Microb. Tech., 25, 613-621 (1999).

Joshi, S., Bharucha, C., Desai, A. J., Production of biosurfactant and antifungal compound by fermented food isolate Bacillus subtilis 20B. Bioresour. Technol., 99, 4303-4603 (2008). 
Kluge, B., Vater, J., Salnikow, J., Eckart, K., Studies on the biosynthesis of surfactin, a lipopeptide antibiotic from Bacillus subtilis ATCC 21332. FEBS Lett, 231, 107-110 (1998).

Kosaric, N., Biosurfactants in Industry. Pure. Appl. Chem., 64, 1731-1737 (1992).

Liu, J., Huang, X., Lu, L., Xu, J., Wen, Y., Yang, D., Zhou, Q., Comparison between waste frying oil and paraffin as carbon source in the production of biodemulsifier by Dietzia sp. S-JS-1. Bioresour. Technol., 100, 6481-6487 (2009).

Makkar, R. S., Cameotra, S. S., Utilization of molasses for biosurfactant production by two Bacillus subtilis strains at thermophilic conditions. J. Am. Oil. Chem. Soc., 74, 887-889 (1997).

Makkar, R. S., Cameotra, S. S., Production of biosurfactant at mesophilic and thermophilic conditions by a strain of Bacillus subtilis. J. Ind. Microbiol. Biot., 20, 48-52 (1998).

Makkar, R. S., Cameotra, S. S., Biosurfactant production by microorganisms on unconventional carbon sources - a review. J. Surfactants. Deter., 2, 237-241 (1999).

Mulligan, C. N., Environmental applications for Biosurfactants. Environ. Pollut., 133, 183-198 (2005).

Peypoux, F., Bonmatin, J. M., Wallach, J., Recent trends in the biochemistry of surfactin. Appl.
Microbiol. Biotechnol., 51, 553-563 (1999).

Raza, Z. A., Khan, M. S., Khalid Z. M., Rehman, A., Production kinetics and tensiometric Characteristics of biosurfactant from a Pseudomonas aeruginosa mutant grown on waste frying oils. Biotechnol. Lett., 28, 1653-1631 (2006).

Roe, J. H., The determination of sugar in blood and spinal fluid with anthrone reagent. J. Biol. Chem., 212, 335-343 (1955).

Rosenberg, E., Ron, E. Z., High molecular mass microbial surfactants. Appl. Microbiol. Biot., 52, 154-162 (1999).

Seydlová, G., Svobodová, J., Review of surfactin chemical properties and the potential biomedical applications. Cent. Eur. J. Med., 3, 123-133 (2008).

Shreve, G. S., Inguva, S., Gunnam, S., Rhamnolipid biosurfactant enhancement of hexadecane biodegradation by Pseudomonas aeruginosa. Mol. Mar. Biol, Biotech., 4, 331-339 (1995).

Steller, S., Sokoll, A., Wilde, C., Bernhard, F., Franke, P., Vater, J., Initiation of surfactin biosynthesis and the role of the SrfD-thioesterase protein. Biochemistry, 43, 11331-11343 (2004).

Zigoneanu, I. J., Williams, L., Xu, Z., Sabliov, C. M., Determination of antioxidant components in rice bran oil extracted by microwave-assisted method. Bioresour. Tech., 99, 4910-4918 (2008). 